[Agr. 'Biol. Chem., Vol. 31, No. 3, p. $301 \sim 308,1967$ ]

\title{
Direct Colorimetric Method for the Determination of Free Ammonia in Blood
}

\author{
By Keiichiro Muramatsu \\ Department of Agricultural Chemistry, Faculty of Agriculture, Shizuoka University, \\ Iwata, Shizuoka-ken \\ Received October 3, 1966
}

\begin{abstract}
In an attempt to develope a rapid and simple method for the colorimetric determination of free ammonia in blood, the conditions for the indophenol reaction, the direct application of it for the determination of blood ammonia, and the interferences of a number of substances for the color development, have been investigated. This color reaction was sensitive enough for the direct method, but must be done under the limiting conditions, for the interfereing substances are contained in blood. Interferences of many amino acids for the color development were observed, but the effects differed among different amino acids, and many of substances other than amino acids showed very little or no intereference. Under the conditions applied, neither the amino acids nor other substances in blood interfered the method.
\end{abstract}

In general, free ammonia in blood has been determined by the microdiffusion technique of Conway ${ }^{11}$ or by the diffusion technique of Seligson and Hirahara. ${ }^{21}$ Recently the latter method is widely applied to human blood. The method is based on the diffusion of blood ammonia by alkalization in a diffusion bottle using rotator followed by the colorimetric determination of the ammonia with Nessler reagent. Inasmuch as this diffusion method requires a few $\mathrm{ml}$ of blood for the duplicate or the triple test, it is unsuited sometimes for adapt to small amounts of blood, such as may be obtained from small laboratory animals. In addition, the diffusion method gives occasionally erratic results without skill. If free ammonia in blood is possibly estimated directly by a colorimetric procedure, a diffusion process may be omitted and the reproducible results may also be obtained. The colori-

1) E. J. Conway, "Microdiffusion Analysis and Volumetric Error,' ed. 3, Crosby, Lockwood \& Son, Ltd. London, 1950.

2) D. Seligson and K. Hirahara, J. Lab. Clin. Med., 49, 926 (1957). metric determination of ammonia from various sources has been done generally by Nessler method $^{3 \prime}$ or by indophenol reaction. ${ }^{3 \sim 13 !}$ It is known that the indophenol reaction is superior to Nessler method, because the blue color of indophenol which is formed by the reaction of ammonia, phenol and hypochlorite in an alkaline medium is stable, and more intense than the unstable yellowish orange color yield from Nessler reaction. ${ }^{5,81}$ Some

3) S. Jacobs, in D. Glick (Editors). "Methods of Biochemical Analysis", vol 13, John Wiley \& Sons, Inc. New York, 1965, p. 241.

4) P. Thomas, Bull. Soc. Chim., 11, 796 (1912); ibid., 13, 398 (1913).

5) D. D. Van Slyke and A. Hiller, J. Biol. Chem., 102, 499 (1933); D. D. Van Slyke and J. Sendroy Jr., ibid., 102, 505 (1933).

6) H. Borsook, ibid., 110, 481 (1935).

7) J. A. Russell, ibid., 156, 457 (1944).

8) J. P. Riley, Anal. Chim. Acta, 9, 575 (1953).

9) E. D. Noble, Anal. Chem., 27, 1413 (1955).

10) D. Exley, Biochem. J., 63, 496 (1956).

11) W. T. Bolleter, C. J. Bushman and P. W. Tidwell, Anal. Chem., 33, 592 (196I).

12) K. Konitzer and S. Voigt, Clin. Chim. Acta, 8, 5 (1963).

13) G. E. Miller and J.D. Rice, Am. J. Clin. Path., 39, 97 (1963). 
workers ${ }^{14 \sim 19 /}$ have reported that the color development of indophenol on adding sodium nitroprusside as a catalyst is several times greater than that without the catalyst. The method of Lubochinsky and Zalta ${ }^{11)}$ is a representative procedure employed it. The method requires more than $1 \mu \mathrm{g}$ of ammonia nitrogen per sample and more erratic result may occur at concentration below the level. Since the ammonia nitrogen level in blood is approximately $1 \mu \mathrm{g}$ per $\mathrm{ml}_{,}{ }^{21}$ it seemed desirable to improve more the sensibility for direct determination. However, this indophenol reaction cannot be applied without limitation for the direct determination, because it has been observed that certain substances, such as amino acids, in blood interfere the color formation. ${ }^{7,8,11}$

The following experiments were made, therefore, to find the suitable conditions of of colorimetric procedure which applies indophenol reaction for free ammonia in small amounts of blood. In addition, the interference effects of a number of amino acids and other substances on the color development were tested with respect to the limited range of the method. The method applied to blood was in agreement with the diffusion method of Seligson and Hirahara.

\section{MATERIALS}

Alkaline solution. Mix 1 liter of $0.1 \mathrm{M} \mathrm{Na}_{2} \mathrm{HPO}_{4}$ and $80 \mathrm{ml}$ of $1 \mathrm{~N} \mathrm{NaOH}$, and adjust to $\mathrm{pH} 11.7$. Final $\mathrm{pH}$ of the reaction mixture becomes about 11 .

Phenol, $3 \%$ solution. Dissolve $3 \mathrm{~g}$ of distilled phenol in $100 \mathrm{ml}$ of distilled water. The addition

14) B. Lubochinsky and J. P. Zalta, Bull, soc. chim. biol., 36, 1363 (1954).

15) R. H. Brown, G. D. Duda, S. Korkes and P. Handler, Arch. Biochem. Biophy., 66, 301 (1957).

16) K. Yagi and J. Okuda, "Protein, Nucleic acid and Enzyme", 4, 139 (1959). Kyoritsu Shuppan Co. Ltd., Tokyo.

17) J. K. Fawcett and J.E. Scott, Brit. J. Clin. Path., 13, 156 (1960).

18) J. L. Ternberg and F. B. Hershey, J. Lab. Clin. Med., 56, 766 (1960).

19) A. L. Chaney and E. P. Marbach, Clin. Chem. 8, $130(1962)$. of sodium hydroxide solution to phenol was avoided in the present work, because it causes are coloring.

Sodium nitroprusside, $\mathbf{0 . 0 5 \%}$ solution. Dissolve $0.05 \mathrm{~g}$ of sodium nitroprusside in $100 \mathrm{ml}$ of distilled water. Preserve in a refrigerator.

Antiformin, 2\% solution. Dilute $20 \mathrm{ml}$ of commercial "Antiformin", alkaline solution of sodium hypochlorite containing $10 \%$ active chlorine, to $100 \mathrm{ml}$ with distilled water.

Standard ammonia solution. Prepare a stock standard solution by dissolving $118 \mathrm{mg}$ of recrystalized dry $\left(\mathrm{NH}_{4}\right)_{2} \mathrm{SO}_{4}$ in 1 liter of distilled water. Pipet $10 \mathrm{ml}$ of that solution into a $100 \mathrm{ml}$ of volumetric flask and make up to mark. This working standard solution contains $2.5 \mu \mathrm{g}$ of $\mathrm{NH}_{3}-\mathrm{N}$ per ml.

\section{PRELIMINERY EXPERIMENT}

Effects of the various factors on the color development of indophenol reaction were determined to obtain the optimum condition.

Effect of pH. It is known that the color development of indophenol is influenced sensitively by $\mathrm{pH}$ in the reaction mixture.7,11,14,16) The maximum color formation was obtained at about $\mathrm{pH} \mathrm{11}$, and was decreased sharply at a $\mathrm{pH}$ lower than 10 and at a $\mathrm{pH}$ higher than 12 (Fig. 1).

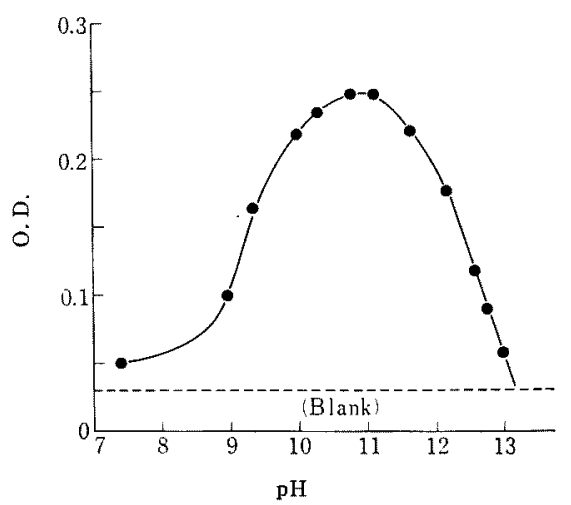

FIG. 1. Effect of pH on Color Development.

The $\mathrm{pH}$ is maintained with appropriate buffer mixtures, and all other conditions are as described under the procedure in text, using $1.25 \mu \mathrm{g}$ of $\mathrm{NH}_{3}$ N. $5 \mathrm{~mm}$ cell.

Phenol. The concentration of phenol necessary for the full color development was determined by varying amounts of phenol in the reaction mixture 


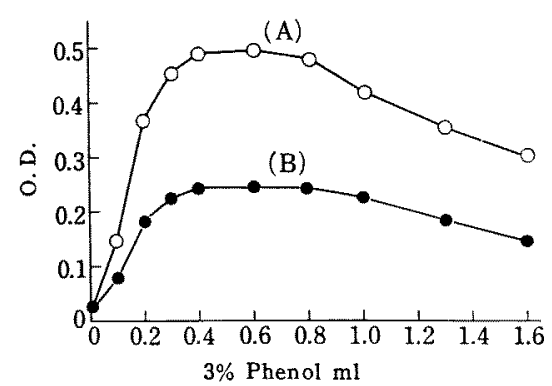

FIG 2. Effect of Phenol Concentration on Color Development.

(A) $2.5 \mu \mathrm{g}$ and (B) $1.25 \mu \mathrm{g}$ of $\mathrm{NH}_{3}-\mathrm{N}, 5 \mathrm{~mm}$ cell.

(Fig. 2). The full color formation was obtained on addition of $0.4 \sim 0.8 \mathrm{ml}$ of $3 \%$ phenol. Outside this range, the color formation was decreased.

Sodium nitroprusside. Similar experiment was made by the addition of varying amounts of sodium nitroprusside in the reaction mixture (Fig. 3). The color intensity was elevated rapidly with increasing amount of the reagent, but did not change in the net value above $0.2 \mathrm{ml}$ of it. Large amount of this reagent merely produced an increase in the reagent blank.

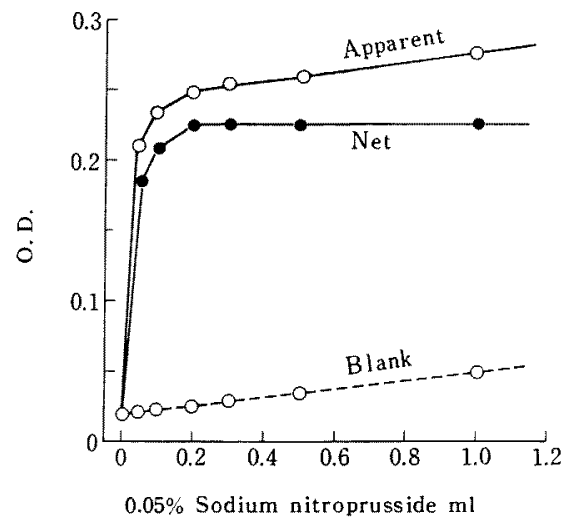

Fig. 3. Effect of Sodium nitroprusside Concentration on Color Development.

$1.25 \mu \mathrm{g}$ of $\mathrm{NH}_{3}-\mathrm{N} .5 \mathrm{~mm}$ cell.

Antiformin. In a similar manner the effect of the variation of the amount of antiformin was determined in the reaction mixture containing the different amounts of ammonia (Fig. 4). When $4 \%$

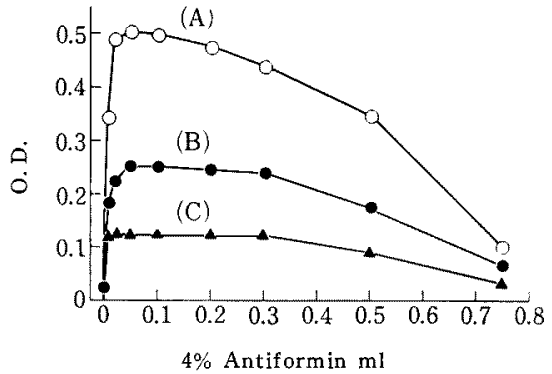

FIG. 4. Effect of Antiformin Concentration on Color Development.

(A) $2.5 \mu \mathrm{g}$, (B) $1.25 \mu \mathrm{g}$ and (C) $0.625 \mu \mathrm{g}$ of $\mathrm{NH}_{3}$ N. $5 \mathrm{~mm}$ cell.

antiformin solution was used, the optimum amount was over a wide range, $0.05 \sim 0.3 \mathrm{ml}$, with low level of ammonia, but was critical at a narrow range, $0.05 \sim 0.1 \mathrm{ml}$, with high level of it. In presence of large amount of antiformin, color formation was depressed greatly.

Temperature. The rate of color development was increased rapidly with elevating of the temperature (Fig. 5). At $100^{\circ} \mathrm{C}, 80^{\circ} \mathrm{C}$ and $60^{\circ} \mathrm{C}$ maximum color was attained in about 2,3 and 8 minutes, respectively. The color intensity at $100^{\circ} \mathrm{C}$, thereafter fell off gradually with heating time, but the full color at $80^{\circ} \mathrm{C}$ and $60^{\circ} \mathrm{C}$ remained constant above 1 hour. Without heating, the maximum color could not be obtained at short time, e.g. to obtain the full color at room temperature $\left(30^{\circ} \mathrm{C}\right)$, it was required to stand

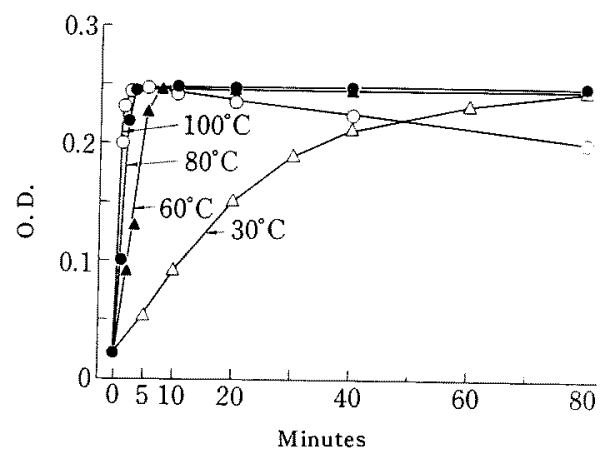

FIG. 5. Effect of Heating Temperature and Time on Color Development.

$1.25 \mu \mathrm{g}$ of $\mathrm{NH}_{3}-\mathrm{N} .5 \mathrm{~mm}$ cell. 


\section{Table I. EFFect of Sequence of AdDition of Reagents on Color Development}

Adding sequence of reagents*1)

$\mathrm{NaOH}$, Phenol, Catalyst and $\mathrm{NaOCl}$ (control)

Phenol, $\mathrm{NaOH}$, Catalyst and $\mathrm{NaOCl}$

Catalyst, $\mathrm{NaOH}$, Phenol and $\mathrm{NaOCl}$

Phenol, Catalyst, $\mathrm{NaOCl}$ and $\mathrm{NaOH}$

$\mathrm{NaOCl}, \mathrm{NaOH}$, Phenol and Catalyst

$\mathrm{NaOCl}$, Phenol, Catalyst and $\mathrm{NaOH}$

*1) NaOH: Alkaline solution, Catalyst: Na-nitroprusside,

*2) Values are expressed as $\%$ of the control. for 60 minutes or more. A 10 minutes heating period at $80^{\circ} \mathrm{C}$ was selected as the optimal time for color formation. The developed color was very stable, and the color was not changed for 24 hours in room temperature.

Sequence of addition of reagents. The sequence of the addition of reagents had a marked influence on color development (Table I). No color formation was observed when antiformin was added first, and the full color development was not obtained when alkaline solution was added last. Anyway, alkaline solution, phenol or sodium nitroprusside must be added and mixed well, before the addition of antiformin. The first addition of alkaline solution did not cause any loss of ammonia.

\section{EXPERIMENTAL PROCEDURE}

Condition of color development. On the basis of the above information, the condition adopted for colorimetric determination of ammonia is as follows: Place a $1.0 \mathrm{ml}$ of sample, containing not more than $2 \sim 3 \mu \mathrm{g}$ of $\mathrm{NH}_{3}-\mathrm{N}$, in a stoppered test tube, and add to it $2 \mathrm{ml}$ of the alkaline solution, $0.5 \mathrm{ml}$ of $3 \%$ phenol, $0.25 \mathrm{ml}$ of $0.05 \%$ sodium nitroprusside, shake well, then add $0.25 \mathrm{ml}$ of $2 \%$ antiformin, and mix. Close the glass stopper of the tube and place it in a water bath at $80^{\circ} \mathrm{C}$ for 10 minutes, cool in tap water the developed color in 5 or $10 \mathrm{~mm}$ cell using a 610 $\mathrm{m} \mu$ filter. Run a reagent blank using water instead of sample. Calculate the difference in the optical density between experimental and blank, and determine the concentration of ammonia in the sample by reference to a standard curve which is obtained using the working standard of ammonium sulfate. This curve showed the linear relationship with either the 5 or $10 \mathrm{~mm}$ cell (Fig. 6). The optical density of for about 5 minutes. Measure the optical density of
Color density*2; \%

100

100

100

86

0

0
$\mathrm{NaOCl}$ : Antiformin

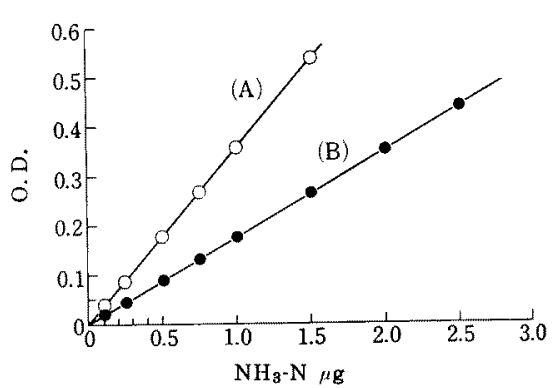

FIG. 6. Standard Curve for the Determination on Ammonia.

(A) $10 \mathrm{~mm}$ and (B) $5 \mathrm{~mm}$ cell.

reagent blank was given values at the range of $0.02 \sim$ 0.04 in $5 \mathrm{~mm}$ cell. Duplicate determinations by this procedure agreed almost invariably within 3 per cent.

Treatment of blood samples. Place an aliquot of ice cold $10 \%$ trichloroacetic acid (TCA) in a centrifuge tube, and add rapidly the equal volume of freshly drown oxalated or heparinized whole blood (add $2 \mathrm{mg}$ of potassium oxalate or $40 \mu \mathrm{l}$ of $1 \%$ sodium heparinate per $\mathrm{ml}$ of blood). This treated blood solution (1:1) was immediately mixed well with glass rod, and the precipitated protein was removed by centrifugation. An aliquot of the supernatant fuid of less than $100 \sim 150 \mu \mathrm{l}$, owing to the interfering effect of other substances containing in blood (see Fig. 7), was introduced in a stoppered graduated test tube, and neutralized by adding an approximately equal volume of $0.1 \mathrm{~N} \mathrm{NaOH}$ (if an indicator is needed, use methyl orange ${ }^{10}$ ), and the solution was then make up to a volume of $1.0 \mathrm{ml}$ with water and the ammonia containing in it was determined by the procedure outlined above. 


\section{RESULTS}

\section{Blood Amounts and Color Formation}

The effect of the amounts of blood sample on the color development was determined with graded levels of TCA treated blood (1:1) of man and rat. As shown in Fig. 7, the curves in both samples were linear up to $100 \sim 150 \mu l$ of treated blood, but above this concentration, the curves gradually fell down. These decreased curves are due to the substances in blood which might interfere the color formation as described below. In any case the application of this direct method must be at least done using the sample of which concentration in range to give the straight line.

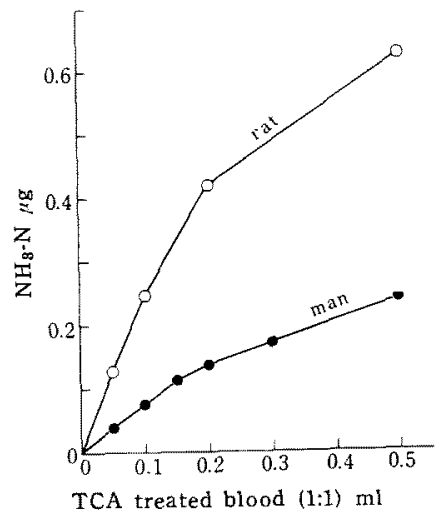

FIG. 7. Relationship between Amounts of Blood Sample and Color Development.

Each point is the mean of not less than three samples.

\section{Recovery of Added Ammonia}

Recovery experiments were performed by adding known amounts of ammonia to varying levels of human and rat blood. The average recoveries are given in Table II. The mean recovery at the amounts below $100 \sim$ $150 \mu 1$ of TCA treated blood (1:1) was ranged from about 95 98\% of that added, but the increasing levels of the sample above that, caused a significant decrease of the recovery in both samples.
TABLE II. RECOVERY OF AMMONIA ADDED TO HUMAN BLOOD*1)
TCA treated blood (1:1) $\mathrm{ml}$

0.05

0.1

$0.1^{* 31}$

0.15

0.2

0.5 $\%$

$98 \pm 3$

$96 \pm 4$

$97 \pm 5$

$95 \pm 4$

$87 \pm 2$

$79 \pm 4$
Ammonia recovered $* 2$,

*1) $1.25 \mu \mathrm{g}$ of $\mathrm{NH}_{3}-\mathrm{N}$ is added to each blood sample.

*2) mean \pm S. D. of 6 samples.

*3) $0.25 \mu \mathrm{g}$ of $\mathrm{NH}_{3}-\mathrm{N}$ is added.

\section{Comparison of Direct and Diffusion Method}

Fifteen whole blood from healthy students who might be expected to have normal blood ammonia levels were analyzed in parallel with the present colorimetric procedure and the diffusion method of Seligson and Hirahara. ${ }^{2)}$ Good agreement was obtained between the two methods, as presented in Table III. An average values of 0.92 and $0.96 \mathrm{NH}_{3}-\mathrm{N} \mu \mathrm{g} / \mathrm{ml}$ blood were obtained by the direct colorimetric and the diffusion method, respectively. These values obtained by the present experiments were slightly lower than those found by Seligson and Hirahara, ${ }^{21}$ who reported that the average ammonia content of whole blood in several hospitalized patients free of liver disease was $1.37(0.75 \sim 1.96) \mu \mathrm{g} / \mathrm{ml}$.

Table III. Comparison of Direct Colorimetric AND DIFFUSION METHOD

Free ammonia in human whole blood, ${ }^{* 1}$, $\mathrm{NH}_{3}-\mathrm{N} \mu \mathrm{g} / \mathrm{ml}$

$\begin{array}{lcc} & \text { Direct colorimetric } & \text { Diffusion*2) } \\ \text { Mean } & 0.92 & 0.96 \\ \text { S. D. } & 0.34 & 0.25 \\ \text { Range } & 0.62 \sim 1.35 & 0.50 \sim 1.30 \\ * 1) & 15 \text { healthy students are used. } \\ * 2 \text { ) Into the diffusion bottles are placed } 1 \mathrm{~g} \text { of al- } \\ \text { kaline mixture }\left(\mathrm{K}_{2} \mathrm{CO}_{3}, \mathrm{KHCO}_{3} 2: 1\right), 1 \mathrm{ml} \text { of } \\ \text { water and } 0.5 \mathrm{ml} \text { of freshly drawn whole blood. } \\ \text { The samples are rotated for } 30 \mathrm{~min} \text {, and dif- } \\ \text { fused ammonia is determined by the indo- } \\ \text { phenol method described here. }\end{array}$




\section{Interference Substances}

A number of amino acids and other substances containing in blood and some foreign substances were tested for the possibility of these interferences with the determination of ammonia by direct colorimetric method. Tests were done by adding $0.01 \sim 5.0 \mu$ mole of the substance to a solution containing $1.25 \mu \mathrm{g}$ of $\mathrm{NH}_{3}-\mathrm{N}$. The results are given in Table IV

Under the condition of this test, serious interferences were observed by the presence of many amino acids, but there were marked differences in each other. From the differences of the interference, the amino acids were divided into groups:

(1) Cystein, histidine and phenylalanine, which depress completely the color development by adding above $2 \mu \mathrm{mole}$; and cystine which develops some interference at adding level of $0.05 \mu$ mole. The interfering effect of this group is greatest among them. (2) Methionine, tyrosine, tryptophan, proline and serine, which eliminate the color at $5 \mu$ mole level; (3) aspartic acid, threonine, hydroxyproline, asparagine, valine and ornithine, and (4) glycine, alanine, isoleucine, homoserine, glu-

TABLE IV. INTERFERENCE OF AMINo ACIDS AND OTHER SUBSTANCES For THE Color DEVELOPMENT OF INDOPHENOL*1\}

(to be continued)

Added amino acids $\mu$ mole

Amino acids
Cysteine
Histidine
Phenylalanine
Cystine
Methionine
Tyrosine
Tryptophan
Proline
Serine
Aspartic acid
Threonine
Hydroxyproline
Asparagine
Valine
Ornithine
Glycine
Alanine
Isoleucine
Homoserine
Glutamic acid
Lysine
Arginine
Leucine
Citrulline
Glutamine
$\beta$-Alanine
Taurine
$\gamma$-Aminobutyric acid
$\varepsilon$-Aminocaproic acid

\begin{tabular}{|c|c|c|c|c|c|c|}
\hline & & mo & reco & $\mathrm{ed}$ & & \\
\hline 0.01 & 0.05 & 0.1 & 0.5 & 1.0 & 2.0 & 5.0 \\
\hline 100 & 96 & 91 & 51 & 28 & 0 & 0 \\
\hline 100 & 96 & 90 & 60 & 26 & 0 & 0 \\
\hline 100 & 100 & 95 & 72 & 43 & 0 & 0 \\
\hline 100 & 91 & 87 & 70 & 60 & 20 & - \\
\hline & 105 & 93 & 65 & 45 & 15 & 0 \\
\hline & 100 & 96 & 80 & 50 & - & - \\
\hline & 102 & 96 & 65 & 54 & 30 & 0 \\
\hline & 100 & 97 & 60 & 40 & 16 & 0 \\
\hline & 100 & 100 & 75 & 56 & 23 & 0 \\
\hline & 100 & 94 & 82 & 75 & 50 & 18 \\
\hline & 100 & 98 & 80 & 74 & 60 & 27 \\
\hline & 100 & 95 & 84 & 74 & 58 & 33 \\
\hline & & 100 & 92 & 84 & 70 & 20 \\
\hline & & 100 & 90 & 78 & 60 & 32 \\
\hline & & 98 & 88 & 80 & 65 & 52 \\
\hline & & 100 & 94 & 80 & 67 & 70 \\
\hline & & 101 & 90 & 85 & 80 & 63 \\
\hline & & 100 & 99 & 89 & 80 & 60 \\
\hline & & 100 & 100 & 100 & 89 & 65 \\
\hline & & 100 & 100 & 97 & 90 & 70 \\
\hline & & 101 & 98 & 94 & 88 & 71 \\
\hline & & 98 & 95 & 92 & 90 & 83 \\
\hline & & 100 & 100 & 98 & 95 & 82 \\
\hline & & 103 & 93 & 90 & 90 & 84 \\
\hline & & 100 & 100 & 100 & 97 & 94 \\
\hline & & 100 & 104 & 110 & 124 & 144 \\
\hline & & 103 & 108 & 115 & 134 & 213 \\
\hline & & 100 & 103 & 108 & 118 & 160 \\
\hline & & 100 & 102 & 105 & 117 & 160 \\
\hline
\end{tabular}

Amino acids in human plasma*2) $\mu$ mole $/ 0.05 \mathrm{ml}$

$$
\begin{array}{ll}
0.002 & \sim 0.012 \\
0.002 & \sim 0.012 \\
0.0015 & \sim 0.01 \\
0.0005 & \sim 0.0035 \\
0.002 & \sim 0.007 \\
0.001 & \sim 0.007 \\
0.006 & \sim 0.025 \\
0.0015 & \sim 0.01 \\
0.00004 & \sim 0.001 \\
0.004 . & \sim 0.015 \\
& \\
0.0022 \\
0.008 & \sim 0.018 \\
0.002 & \sim 0.003 \\
0.005 & \sim 0.036 \\
0.015 & \sim 0.042 \\
0.002 & \sim 0.016 \\
0.0015 & \sim 0.004 \\
0.005 & \sim 0.02 \\
0.0035 & \sim 0.0085 \\
0.004 & \sim 0.02 \\
0.0015 \\
0.015 & \sim 0.033 \\
0.001 & \sim 0.003
\end{array}
$$

Total $0.086 \sim 0.31$ 
TABLE IV.

Added substances $\mu$ moles

Substances
Glutathione (reduced)
Urea
Uric acid
Allantoin
Creatine
Creatinine
Glucose
Fructose
Pyruvic acid
$\alpha$-Ketoglutaric acid
Citric acid
Succinic acid
Fumalic acid
Lactic acid

\begin{tabular}{|c|c|c|c|c|c|}
\hline \multicolumn{5}{|c|}{ Ammonia recovered $\%$} & \multirow{2}{*}{$\begin{array}{l}\text { Substances in human } \\
\text { plasma*3) } \mu \text { mole } / 0.05 \mathrm{ml}\end{array}$} \\
\hline 0.1 & 0.5 & 1.0 & 2.0 & 5.0 & \\
\hline \multirow[t]{7}{*}{103} & 96 & 92 & 79 & 69 & 0.066 \\
\hline & & & & 100 & 0.26 \\
\hline & & & & 100 & 0.007 \\
\hline & & 100 & 104 & 118 & 0.001 \\
\hline & & 100 & 103 & 108 & 0.015 \\
\hline & & & & 100 & 0.006 \\
\hline & 100 & 98 & 95 & 92 & 0.244 \\
\hline 105 & 98 & 94 & 92 & 90 & 0.02 \\
\hline \multirow[t]{6}{*}{100} & 98 & 96 & 80 & 71 & 0.004 \\
\hline & & 100 & 98 & 90 & 0.006 \\
\hline & & & & 100 & 0.006 \\
\hline & & & & 100 & 0.002 \\
\hline & & & & 100 & \\
\hline & & & & 100 & 0.14 \\
\hline
\end{tabular}

*1) Interferences are expressed as $\%$ of the ammonia which is recovered when various amounts of the substance were added to a solution containing $1.25 \mu \mathrm{g}$ of $\mathrm{NH}_{3} \mathrm{~N}$.

*2) These values are calculated from the data of Westall.20

*3) Biochemists' Handbook. 21)

tamic acid, lysine, arginine, leucine, citrulline and glutamine, which retaine the color to the extent of $20 \sim 50 \%$ and above $60 \%$ by adding $5 \mu$ mole, respectively. Of these amino acids examined, glutamine had the lowest effect and it showed no effect below $2 \mu$ mole. In contrast, (5) $\beta$-alanine, taurine, $\gamma$-aminobutyric acid and $\varepsilon$-aminocaproic acid show the negative interference. The color development increases as the graded levels of these amino acids. These amino acids have amino group on the site apart from $\alpha$-position. Taurine caused an increase of more than 2 fold that of control by adding $5 \mu$ mole. The interference of glutathione was an equivalent degree to that of (3) group. It should be noted, however, that amino acids at the adding level of 0.1 $\mu$ mole and below it exerted no effects, except a few amino acids.

The effects of the other substances examined on the color development were much lower than those of amino acids. Glucose, fructose and some keto acids such as pyruvic and $\alpha$ ketoglutaric acid, interfered to a little extent when added at the high levels. Compounds found not to interfere even when added to the high levels were urea, uric acid, creatine, creatinine and many organic acids. Allantoin caused slight increase of the color formation when added at the high level.

\section{DISCUSSION}

The present experiments showed that many amino acids had serious interferences for the sensitive indophenol reaction, but the other substances had very little or no effect. It may be suggested, therefore, that the interferences of the color intensity with high amounts of blood (Fig. 7), and the decreases of the recovery of added ammonia to blood (Table II), are essentially due to the amino acids in blood.

The contents of amino acids and other substances in human plasma are shown in the last colume of Table IV as a reference. ${ }^{20,211}$

20) R. G. Westall, in J. T. Holden (Editor), "Amino Acid Pools", Elsevier Co. Amsterdam, 1962, p. 198. 839. 
The content of each amino acid in $50 \mu \mathrm{l}$ blood which is applied to the direct method is very small, even these total contents are in the range between $0.08 \sim 0.3 \mu$ mole. Accordingly, under this condition applied, it is probable that amino acids in the blood have little or no measurable effect for the color development. Actually, in order to ascertain whether this suggestion is reasonable, a test of the recovery of adding ammonia was carried out by the addition of the amino acid mixtures equivalent to those in $10,50,75$ and $100 \mu 1$ of blood by similar manner described above. These mixtures were combined using the highest value of each amino acid in the reference of the Table. The results indicated that the recoveries of adding ammonia were $100,96,90$ and $86 \%$, respectively. It means that the interference of amino acids in blood can be disregarded essentially under the condition in which less than $50 \mu \mathrm{l}$ of blood is used.

Salts and other substances containing in blood which was not examined herein will lead probably to no erroneous results under the estimating conditions.

This colorimetric technique is also possible to be applied for the direct determination of ammonia in biological fluids and tissues other than blood, under the suitable conditions. Of cource, this method is not expected as a precise method itself, but it may be recommended as a simple and rapid method for estimating ammonia in blood.

Acknowledgement. The author wishes to thank Miss Tuturoöng M. Ellen for her assistance in this work. 